\title{
A Study on Acute Kidney Injury in Intensive Care Setting
}

\author{
Dr. S.Sivakumar ${ }^{1}$ M.D., Dr. B.Elavazhagan ${ }^{2}$ M.D., \\ ${ }^{1}$ Associate Professor, Department Of General Medicine, Government Thiruvannamalai Medical College And \\ Hospital \\ ${ }^{2}$ Senior Resident, Department Of General Medicine, Government Thiruvannamalai Medical College And \\ Hospital
}

\begin{abstract}
Introduction: Acute kidney injury is not a single disease but a terminology for a group of conditions that have similar diagnostic features, importantly, an elevation in the blood urea nitrogen (BUN) level and/or an elevation in the plasma or serum creatinine (S.Cr) concentration, often associated with a decrease in urine volume. AKI can vary in severity from asymptomatic and transient changes in laboratory measures of glomerular filtration rate $(G F R)$, to exaggerated and rapidly fatal derangements in effective circulating blood volume, electrolyte and acid-base composition of the plasma.

AKI is the cause for 5-7\% of acute care hospital admissions and 30\% of intensive care admissions. The epidemiology of AKI varies enormously between developed and developing regions, because of differences in demographics, social and cultural factors. But recent change in cultural habits, life style changes and social values in developing regions produce the near similar picture as developed countries.

The incidence of AKI has increased by more than fourfold in the United States from 1988 and is calculated to have a yearly incidence of 500 per 100,000 persons, more than the yearly incidence of cerebrovascular accidents. AKI causes a markedly increased risk of death in hospitalized persons, especially in those admitted to the ICU where in patient death rates may be more than $50 \%$.

The term acute renal failure was changed to "acute kidney injury." The term failure denotes only portion of the spectrum of damage to the kidney that occurs clinically. Also the term renal is not well understood in the general population and this makes understanding with patients and their caretakers more difficult; so the term renal failure has been changed to acute kidney injury.

Western literature has lot of data regarding the occurrence and nature of acute kidney injury both in the community and inpatient setting. Sadly we are lagging behind in this regard as there are not many records or reports on this topic. This prompted us to take up this study which would throw light on the present scenario of acute kidney injury in intensive care unit.
\end{abstract}

Aims and objective: 1) To identify the incidence of acute kidney injury, their etiological factors, associated co morbid factors, interventions, and outcome in intensive care setting. 2) To address the factors which predict the mortality in acute kidney injury.

Materials and methods

Study design: Prospective observational study.

Study place: Medical Intensive Care Unit (MICU) in Government Thiruvannamalai Medical College and Hospital,

Study duration: March 2016 to August 2016 (6 months).

Study population: Those who were admitted in MICU in that period, and also having acute kidney injury.

Inclusion criteria:

According to RIFLE criteria

- Patients who developed acute kidney injury during the hospital stay.

- Patients who developed acute kidney injury in the community.

- Patients who developed newer insult to a pre existing disease.

Exclusion criteria:

- $\quad$ CKD patients who are in maintenance hemodialysis.

- Patients who got admitted and expired within 24 hours.

- $\quad$ Those who are not willing for the study.

Statistical analysis:

Statistical analysis was performed using IBM SPSS version 20

Summary and conclusion

Acute kidney injury, a common problem in ICU, has a strong impact in the mortality and morbidity. Although there are rampant studies available in the west, there are less than a handful of studies in south India. We had few similarities and dissimilarities in comparison to the western literature. 
Results comparable to study done elsewhere:

- Incidence of AKI is $11.7 \%$

- Mortality rate is $51.8 \%$

- Most common causes of AKI are sepsis, shock, and hepato renal syndrome.

- Predictors of mortality are persistent oliguria requiring renal replacement therapy, hypotension and ventilator support.

- Incidence of AKI is more than acute on chronic kidney disease. Results dissimilar to study done elsewhere:

- Severity of AKI as per RIFLE did not correlate with mortality.

- Patients in RIFLE $(R)$ were less in number.

- Age had no say in the mortality.

- Coexistent diabetes and hypertension did not influence the mortality.

In short, infections and hypotension are the most common cause of mortality. Diligent care should be taken to find the etiology and to maintain fluid homeostasis. Patients who are oliguric and/or on ventilator should be managed with special precautions, as they are significant predictors of mortality.

Keywords: Acute Kidney Injury, Creatinine, BUN, FeNa, RIFLE

\section{Introduction}

Acute kidney injury is not a single disease but a terminology for a group of conditions that have similar diagnostic features, importantly, an elevation in the blood urea nitrogen (BUN) level and/or an elevation in the plasma or serum creatinine (S.Cr) concentration, often associated with a decrease in urine volume. AKI can vary in severity from asymptomatic and transient changes in laboratory measures of glomerular filtration rate (GFR), to exaggerated and rapidly fatal derangements in effective circulating blood volume, electrolyte and acid-base composition of the plasma.

AKI is the cause for 5-7\% of acute care hospital admissions and 30\% of intensive care admissions. The epidemiology of AKI varies enormously between developed and developing regions, because of differences in demographics, social and cultural factors. But recent change in cultural habits, life style changes and social values in developing regions produce the near similar picture as developed countries.

The incidence of AKI has increased by more than fourfold in the United States from 1988 and is calculated to have a yearly incidence of 500 per 100,000 persons, more than the yearly incidence of cerebrovascular accidents. AKI causes a markedly increased risk of death in hospitalized persons, especially in those admitted to the ICU where in patient death rates may be more than $50 \%$

The term acute renal failure was changed to "acute kidney injury." The term failure denotes only portion of the spectrum of damage to the kidney that occurs clinically. Also the term renal is not well understood in the general population and this makes understanding with patients and their caretakers more difficult; so the term renal failure has been changed to acute kidney injury.

Western literature has lot of data regarding the occurrence and nature of acute kidney injury both in the community and inpatient setting. Sadly we are lagging behind in this regard as there are not many records or reports on this topic . This prompted us to take up this study which would throw light on the present scenario of acute kidney injury in intensive care unit.

\section{Aims and objectives}

1. To identify the incidence of acute kidney injury, their etiological factors, associated co morbid factors, interventions, and outcome in intensive care setting.

2. To address the factors which predict the mortality in acute kidney injury

Study design: Prospective observational study.

\section{Materials and methods}

Study place: Medical Intensive Care Unit (MICU) in Government Thiruvannamalai Medical College and Hospital, Thiruvannamalai.

Study duration: March 2016 to August 2016 (6 months).

Study population: Those who were admitted in MICU in that period, and also having acute kidney injury.

Inclusion criteria:

According to RIFLE criteria

- Patients who developed acute kidney injury during the hospital stay.

- Patients who developed acute kidney injury in the community.

- Patients who developed newer insult to a pre existing disease. 


\section{Exclusion criteria:}

- CKD patients who are in maintenance hemodialysis.

- Patients who got admitted and expired within 24 hours.

- Those who are not willing for the study.

After getting approval from institutional ethical committee, the study was started in MICU. Patients were given the consent form, and explanation was given. Those who were willing to participate were included in the study.

\section{How was the study conducted?}

In the 6 months, patients who got admitted in MICU were monitored for development of AKI, and those who admitted with AKI were also included in the study.

AKI was diagnosed based on RIFLE criteria.

- We mainly considered the creatinine values for the diagnosis. But urine output was also taken into the data.

- To find out AKI and differentiate acute from acute on chronic renal disease by old records, ultra sonogram and other co morbid factors.

- Elevation of creatinine from baseline values for each patient was demonstrated.

- To differentiate the prerenal from intrinsic renal, the clinical scenario, BUN: Cr ratio, FeNa was taken into consideration.

- The associated co morbid factors, their course of stay, any significant events and the interventions they underwent were also documented.

- In-hospital mortality or improvement has been set as a final point. Attempts were made to find out the etiology in every case.

- Those who were labeled with sepsis include sepsis due to urinary tract infection, soft tissue infection, pneumonia, CNS infections and sepsis of unknown etiology.

- Only medical cases were included in the study. Surgical cases, trauma cases and post operative cases were not included in the study.

\section{Statistical analysis}

Statistical analysis was performed using IBM SPSS version 20. All categorical data were expressed as percentage of the whole. The continuous variables were expressed as Mean \pm Standard Deviation. Univariate analysis was performed using Chi Square test for categorical data and Mann Whitney U test was used for the continuous variables. The significance level was fixed at $\mathrm{p}<0.05$. Adjusted Odds ratio with $95 \%$ Confidence interval was calculated as an estimate of the risk in those variables with statistically significant differences between the groups. Those variables which had $p$ values less than 0.15 in the univariate model entered the multivariate logistic regression in backward conditional method. The odds ratio (Exp [B]) and level of significance $(\mathrm{p})$ were obtained in the regression analysis. Variables with $\mathrm{p}<0.05$ were taken as significant.

\section{Results}

The study was conducted in our MICU for 6 months. The study results were as follows:

During the six month period, total number of MICU admissions was 700.

The total number patients who developed AKI were 83.

The incidence of acute kidney injury was 118 per 1000 admissions.

About $11.9 \%$ of the admissions had AKI in our MICU.

Among the 83 cases, 43 cases were expired and 40 were discharged from MICU.

The mortality rate was $51.8 \%$.

\section{Mortality Rate}

\begin{tabular}{|c|c|c|c|}
\hline TOTAL CASES & DISCHARGED & EXPIRED & MORTALITY \\
\hline 83 & 40 & 43 & $51.8 \%$ \\
\hline
\end{tabular}

Sex Distribution And Their Outcome

\begin{tabular}{|c|c|c|c|c|c|c|}
\hline \multirow{2}{*}{ SEX } & \multicolumn{2}{|c|}{ TOTAL } & \multicolumn{4}{c|}{ OUTCOME } \\
\cline { 2 - 6 } & \multicolumn{2}{|c|}{ Percent } & Number & Percent & Number & Percent \\
\cline { 2 - 6 } & Number & $37.3 \%$ & 15 & $37.5 \%$ & 16 & $37.2 \%$ \\
\hline Female & 31 & $62.7 \%$ & 25 & $62.5 \%$ & 27 & $62.8 \%$ \\
\hline Male & 52 & \multicolumn{2}{|c|}{ Chi square $(\mathrm{X})^{2}=0.001$} & $\mathrm{p}=0.978$ \\
\hline \multicolumn{3}{|l}{} \\
\hline
\end{tabular}


In our study group, among the patients who developed AKI, 52 were males and 31 were females. The percentage was 62.7 for males, 37.3 for females.

The percentage of patients developing AKI is more in males. Among the expired patients 27 were males and 16 were females with a percentage of 62.8 for males and 37.2 for females respectively.

But this had no statistical significance to predict that male gender is a risk factor for mortality in patients with AKI.

Age Distribution In Aki

\begin{tabular}{|c|c|c|c|c|c|c|}
\hline \multirow{2}{*}{$\begin{array}{c}\text { AGE } \\
\text { GROUP }\end{array}$} & \multicolumn{2}{|c|}{ TOTAL } & \multicolumn{4}{c|}{ OUTCOME } \\
\cline { 2 - 6 } & Number & Percent & Number & Percent & Number & Percent \\
\hline$<30$ & 8 & $9.6 \%$ & 6 & $15.0 \%$ & 2 & $4.7 \%$ \\
\hline $30-39$ & 9 & $10.8 \%$ & 1 & $2.5 \%$ & 8 & $18.6 \%$ \\
\hline $40-49$ & 19 & $22.9 \%$ & 7 & $17.5 \%$ & 12 & $27.9 \%$ \\
\hline $50-59$ & 25 & $30.1 \%$ & 16 & $40.0 \%$ & 9 & $20.9 \%$ \\
\hline$>60$ & 22 & $26.5 \%$ & 10 & $25.0 \%$ & 12 & $27.9 \%$ \\
\hline
\end{tabular}

Among the AKI patients, 25 were in the age group of $50-59,22$ were in the age group of more than 60.Among the expired those who were more than 60 years of age and those between 40 - 49 years of age had increased percentage of mortality.

\section{Primary Cause For Admission}

\begin{tabular}{|l|c|c|c|c|c|c|}
\hline \multirow{2}{*}{ ADMITTED FOR } & \multicolumn{2}{|c|}{ TOTAL } & \multicolumn{4}{c|}{ OUTCOME } \\
\cline { 2 - 7 } & Number & Percent & Number & Percent & Number & Percent \\
\cline { 2 - 7 } & 3 & $3.6 \%$ & 3 & $7.5 \%$ & 0 & $0 \%$ \\
\hline ADD & 7 & $8.4 \%$ & 3 & $7.5 \%$ & 4 & $9.3 \%$ \\
\hline CVD & 8 & $9.6 \%$ & 5 & $12.5 \%$ & 3 & $7 \%$ \\
\hline CNS & 1 & $1.2 \%$ & 1 & $2.5 \%$ & 0 & $0 \%$ \\
\hline MALARIA & 13 & $15.6 \%$ & 4 & $10 \%$ & 9 & $20.9 \%$ \\
\hline DCLD & 4 & $4.8 \%$ & 1 & $2.5 \%$ & 3 & $7 \%$ \\
\hline FULMINANT & 10 & $12 \%$ & 4 & $10 \%$ & 6 & $14 \%$ \\
\hline HEPATITIS & 31 & $37.2 \%$ & 15 & $37.5 \%$ & 16 & $37.2 \%$ \\
\hline SEPSIS & 2 & $2.4 \%$ & 2 & $5 \%$ & 0 & $0 \%$ \\
\hline CuSO & 1 & $1.2 \%$ & 0 & $0 \%$ & 1 & $2.3 \%$ \\
\hline SOLANINE & 1 & $1.2 \%$ & 1 & $2.5 \%$ & 0 & $0 \%$ \\
\hline PANCREATITIS & 1 & $1.2 \%$ & 0 & $0 \%$ & 1 & $2.3 \%$ \\
\hline MALIGNANCY & 1 & $1.2 \%$ & 1 & $2.5 \%$ & 0 & $0 \%$ \\
\hline HYPOKALEMIA & \multicolumn{2}{|c|}{} & & & 3 & $2 \%$ \\
\hline
\end{tabular}

The above table shows the various diseases for which patient got admitted. Among these, the patients who got admitted for sepsis were more prone to develop acute kidney injury. In the 83 patients, 31 were admitted for sepsis with a percentage of $37.2 \%$. 13 patients who got admitted for decompensated liver disease developed AKI with a percentage of $15.6 \%$. Among the 83 AKI's, 10 were admitted for primary renal problem with a percentage of $12 \%$. Among the expired patients, $37.2 \%$ were admitted for sepsis and $20.9 \%$ were admitted for DCLD.

The remaining was CNS 7\%, CVD 9.3\% and Fulminant Hepatitis 7\%. Others were ADD, Malaria, Pancreatitis, Copper Sulphate, Solanine poisoning and Hypokalemia.

Co Morbid Factor - Systemic Hypertension In Aki

\begin{tabular}{|c|c|c|c|c|c|c|}
\hline \multirow{2}{*}{ SHT } & \multicolumn{2}{|c|}{ TOTAL } & \multicolumn{3}{c|}{ OUTCOME } \\
\cline { 2 - 6 } & Number & Percent & Number & Percent & Number & Percent \\
\cline { 2 - 6 } & 23 & $27.7 \%$ & 11 & $27.5 \%$ & 12 & $27.9 \%$ \\
\hline YES & 60 & $72.3 \%$ & 29 & $72.5 \%$ & 31 & $72.1 \%$ \\
\hline NO & \multicolumn{2}{|c|}{ Chi square $(X)^{2}=0.002$} & \multicolumn{2}{c|}{$\mathrm{p}=0.967$} \\
\hline
\end{tabular}

Among 83 AKI patients 23 patients had SHT, 60 patients didn't have hypertension with a percentage of $27.7 \%$ and $72.3 \%$ respectively.

In the expired group of patients, 12 had SHT and 31 did not have that, with a percentage of $27.9 \%$ and $72.1 \%$ respectively.

These values did not have statistical significance with a p value of 0.967 . 


\section{Comorbid Factor - T2dm In Aki}

\begin{tabular}{|c|c|c|c|c|c|c|}
\hline \multirow{2}{*}{ T2DM } & \multicolumn{2}{|c|}{ TOTAL } & \multicolumn{3}{c|}{ OUTCOME } \\
\cline { 2 - 6 } & Number & Percent & Number & Percent & Number & Percent \\
\cline { 2 - 6 } & 34 & $59 \%$ & 17 & $42.5 \%$ & 17 & $39.5 \%$ \\
\hline YES & 49 & $41 \%$ & 23 & $57.5 \%$ & 26 & $60.5 \%$ \\
\hline NO & \multicolumn{2}{|c|}{ Chi square $(\mathrm{X})^{2}=0.075$} & \multicolumn{2}{c|}{$\mathrm{P}=0.784$} \\
\hline
\end{tabular}

34 out of 83 patients had diabetes mellitus and 49 didn't have diabetes with a percentage of $59 \%$ and $41 \%$ respectively.

Among the expired patients, 17 had diabetes mellitus and 26 on the other side. $39.5 \%$ of the expired individuals had diabetes. $60.5 \%$ didn't have this co morbid factor.

This is not statistically significant with a $\mathrm{p}$ value of 0.784 .

Spot Urine Sodium In Aki - An Analysis

\begin{tabular}{|c|c|c|c|c|c|c|}
\hline \multirow{3}{*}{$\begin{array}{l}\text { URINE } \\
\text { SODIUM }\end{array}$} & \multirow{2}{*}{\multicolumn{2}{|c|}{ TOTAL }} & \multicolumn{4}{|c|}{ OUTCOME } \\
\hline & & & \multicolumn{2}{|c|}{ Discharged } & \multicolumn{2}{|c|}{ Expired } \\
\hline & Number & Percent & Number & Percent & Number & Percent \\
\hline$<40$ & 28 & $33.7 \%$ & 9 & $22.5 \%$ & 19 & $44.2 \%$ \\
\hline$>40$ & 55 & $66.3 \%$ & 31 & $77.5 \%$ & 24 & $55.8 \%$ \\
\hline & & & \multicolumn{2}{|c|}{ Chi square $(\mathrm{X})^{2}=4.360$} & \multicolumn{2}{|c|}{$\mathrm{p}=0.037 *$} \\
\hline
\end{tabular}

In 83 patients with AKI, 28 patients had spot urine sodium less than 40 and 55 patients had more than 40 and their percentage was $33.7 \%$ and $66.3 \%$ respectively. 24 patients, who died had spot urine sodium more than 40 and 19 had less than 40 with a percentage of $55.8 \%$ and $44.2 \%$ respectively. This had a statistical significance with a $\mathrm{P}$ value of 0.037 , which implies that spot urine sodium $>40$ is a predictor of mortality.

Significance Of Fena In Aki

\begin{tabular}{|c|c|c|c|c|c|c|}
\hline \multirow{2}{*}{ FeNa } & \multicolumn{2}{|c|}{ TOTAL } & \multicolumn{3}{c|}{ OUTCOME } \\
\cline { 2 - 6 } & Number & Percent & Number & Percent & Number & Percent \\
\cline { 2 - 6 } & 29 & $34.9 \%$ & 16 & $40 \%$ & 13 & $30.2 \%$ \\
\hline$<1$ & 54 & $65.1 \%$ & 24 & $60 \%$ & 30 & $69.8 \%$ \\
\hline$>1$ & & \multicolumn{2}{|c|}{ Chi square $(\mathrm{X})^{2}=0.870$} & \multicolumn{2}{c|}{$\mathrm{p}=0.351$} \\
\hline
\end{tabular}

In 83 AKI patients, 54 had FeNa $>1$ and 26 had FeNa<1. The percentage was $65.1 \%$ and $34.9 \%$ respectively. 30 out of 43 expired individuals had $\mathrm{FeNa}>1$ and 13 individuals had $\mathrm{FeNa}<1$. The percentage was 69.8 and $30.2 \%$ respectively. Although the death rate was more in the patients with $\mathrm{FeNa}>1$, it was not statistically significant with the $\mathrm{p}$ value of 0.351 .

Urine Abnormalities In Aki

\begin{tabular}{|c|c|c|c|c|c|c|}
\hline \multirow{2}{*}{$\begin{array}{c}\text { URINE } \\
\text { ROUTINE }\end{array}$} & \multicolumn{2}{|c|}{ TOTAL } & \multicolumn{3}{c|}{ OUTCOME } \\
\cline { 2 - 6 } & Number & Percent & Number & Percent & Number & Percent \\
\cline { 2 - 6 } & 37 & $44.6 \%$ & 14 & $35 \%$ & 23 & $53.5 \%$ \\
\hline NORMAL & 46 & $55.4 \%$ & 26 & $65 \%$ & 20 & $46.5 \%$ \\
\hline SEDIMENT & \multicolumn{3}{|l}{} & \multicolumn{2}{|c|}{ Chi square $(\mathrm{X})^{2}=2.867$} & \multicolumn{2}{c|}{$\mathrm{p}=0.090$} \\
\hline
\end{tabular}

Among the 83 patients, 46 had active sediments in the urine and 37 had no abnormalities with a percentage of $55.4 \%$ and $44.6 \%$ respectively.

In the 43 expired patients, 20 had active sediments and 23 had no sediments with a percentage of $46.5 \%$ and $53.5 \%$ respectively.

The association between this urinary abnormality and death rate is not statistically significant with a $\mathrm{p}$ value of 0.090 .

Urine Output - A Predictor Of Mortality

\begin{tabular}{|c|c|c|c|c|c|c|}
\hline \multirow{3}{*}{$\begin{array}{c}\text { Urine } \\
\text { Output }\end{array}$} & \multirow{2}{*}{\multicolumn{2}{|c|}{ Total }} & \multicolumn{4}{|c|}{ Outcome } \\
\hline & & & \multicolumn{2}{|c|}{ Discharged } & \multicolumn{2}{|c|}{ Expired } \\
\hline & Number & Percent & Number & Percent & Number & Percent \\
\hline $\begin{array}{l}\text { Non } \\
\text { Oliguric }\end{array}$ & 45 & $54.2 \%$ & 29 & $72.5 \%$ & 16 & $37.2 \%$ \\
\hline Oliguric & 38 & $45.8 \%$ & 11 & $27.5 \%$ & 27 & $67.8 \%$ \\
\hline & & & \multicolumn{2}{|c|}{ Chi Square $(\mathrm{X})^{2}=10.398$} & \multicolumn{2}{|c|}{$\mathrm{P}=0.001^{*}$} \\
\hline
\end{tabular}

Out of 83 patients, 38 were oliguric and 45 were non oliguric with $45.8 \%$ and $54.2 \%$ respectively. 
Among the expired, 27 were oliguric and 16 were non oliguric. The percentage was $67.8 \%$ and $37.2 \%$ respectively. Oliguria was one of the predictor of mortality with statistical significance. The p value was 0.001 .

\section{Hypotension And Aki}

\begin{tabular}{|l|c|c|c|c|c|c|}
\hline \multirow{2}{*}{ HYPOTENSION } & \multicolumn{2}{|c|}{ TOTAL } & \multicolumn{4}{c|}{ OUTCOME } \\
\cline { 2 - 7 } & Number & Percent & Number & Percent & Number & Percent \\
\cline { 2 - 7 } & 43 & $51.8 \%$ & 27 & $67.5 \%$ & 16 & $37.2 \%$ \\
\hline NO & 40 & $48.2 \%$ & 13 & $32.5 \%$ & 27 & $62.8 \%$ \\
\hline YES & \multicolumn{2}{|l|}{} & Chi square $(\mathrm{X})^{2}=7.615$ & \multicolumn{2}{c|}{$\mathrm{p}=0.006^{*}$} \\
\hline
\end{tabular}

Among the patients with AKI 40 persons had hypotension and 43 persons didn't have hypotension during the course of hospital stay with a percentage of $48.2 \%$ and $51.8 \%$ respectively.

Out of 43 expired individuals, 27 had hypotension and 16 didn't have that. The percentage was $62.8 \%$ and $37.2 \%$ respectively.

This was statistically significant with a p value around 0.006 . Hypotension is a predictor of mortality in AKI.

\section{Ventilator Support In Aki}

\begin{tabular}{|l|c|c|c|c|c|c|}
\hline \multirow{2}{*}{$\begin{array}{c}\text { Ventilatory } \\
\text { Support }\end{array}$} & \multicolumn{2}{|c|}{ Total } & \multicolumn{4}{c|}{ Outcome } \\
\cline { 2 - 6 } & Number & Percent & Number & Percent & Number & Percent \\
\cline { 2 - 7 } & 46 & $55.4 \%$ & 27 & $67.5 \%$ & 19 & $44.2 \%$ \\
\hline No & 37 & $44.5 \%$ & 13 & $32.5 \%$ & 24 & $55.8 \%$ \\
\hline \multicolumn{3}{|l|}{} & \multicolumn{2}{|c|}{ Chi Square $(\mathrm{X})^{2}=4.559$} & \multicolumn{2}{c|}{$\mathrm{P}=0.033^{*}$} \\
\hline
\end{tabular}

In total no AKI patients, 37 needed ventilator support and 46 didn't need that support. The percentage was $44.5 \%$ and $55.4 \%$ respectively.

In 43 expired patients, 24 were on ventilator support and 19 were not on ventilator with the percentage $55.8 \%$ and $44.2 \%$ respectively.

This increased percentage had statistical significance with $\mathrm{p}$ value of 0.033

Thus ventilator support in AKI patients is a predictor of mortality.

Distribution Of Acute And Acute On Chronic Renal Disease

\begin{tabular}{|l|c|c|c|c|c|c|}
\hline \multirow{2}{*}{ Duration } & \multicolumn{3}{|c|}{ Total } & \multicolumn{3}{c|}{ Outcome } \\
\cline { 2 - 7 } & Number & Percent & Number & Percent & Number & Percent \\
\hline Acute & 46 & $55.4 \%$ & 21 & $52.5 \%$ & 25 & $58.1 \%$ \\
\hline $\begin{array}{l}\text { Acute On } \\
\text { Chronic }\end{array}$ & 37 & $44.6 \%$ & 19 & $47.5 \%$ & 18 & $41.9 \%$ \\
\hline \multicolumn{2}{|r|}{} & \multicolumn{2}{|c|}{ Chi Square $(\mathrm{X})^{2}=0.267$} & \multicolumn{2}{c|}{$\mathrm{P}=0.605$} \\
\hline
\end{tabular}

Patients presented as acute renal failure without pre-existing renal disease were 46 (out of 83) which were $55.4 \%$. Those who had underlying renal disease presenting as acute on pre existing renal disease were 37 out of $83(44.6 \%)$. Among the expired, 25 were acute and 18 were acute on chronic renal disease with $58.1 \%$ and $41.9 \%$ respectively. Although there is increased percentage of acute presentation, it had no statistical significance. The $\mathrm{p}$ value was 0.605 .

Distribution of type of aki:

\begin{tabular}{|l|c|c|c|c|c|c|}
\hline \multirow{2}{*}{ Pathology } & \multicolumn{2}{|c|}{ Total } & \multicolumn{4}{c|}{ Outcome } \\
\cline { 2 - 7 } & Number & Percent & Number & Percent & Number & Percent \\
\cline { 2 - 7 } & 25 & $30.1 \%$ & 14 & $35 \%$ & 11 & $25.6 \%$ \\
\hline Pre Renal & 58 & $69.9 \%$ & 26 & $65 \%$ & 32 & $74.4 \%$ \\
\hline Intrinsic Renal & \multicolumn{2}{|l}{} & \multicolumn{2}{|c|}{ Chi Square $(\mathrm{X})^{2}=0.873$} & \multicolumn{3}{c}{$\mathrm{P}=0.350$} \\
\hline \multicolumn{2}{|l}{}
\end{tabular}

Among the 83 patients, 58 had intrinsic AKI and 25 had prerenal AKI with a percentage of $69.9 \%$ and $30.1 \%$ respectively.

In 43 expired patients 32 had intrinsic renal and 11 had pre renal disease. The percentage was $74.4 \%$ and $25.6 \%$ respectively. This is not statistically significant with a p value of 0.350 .

Distribution Of Severity In Aki

\begin{tabular}{|l|l|l}
\hline Rifle Category & Total & Outcome \\
\hline
\end{tabular}




\begin{tabular}{|l|c|c|c|c|c|c|}
\hline & \multicolumn{3}{|c|}{} & \multicolumn{2}{c|}{ Discharged } & \multicolumn{2}{c|}{ Expired } \\
\cline { 2 - 7 } & Number & Percent & Number & Percent & Number & Percent \\
\hline Rifle $-\mathrm{R}$ & 3 & $3.6 \%$ & 2 & $5.0 \%$ & 1 & $2.3 \%$ \\
\hline Rifle $-\mathrm{I}$ & 36 & $43.4 \%$ & 17 & $42.5 \%$ & 19 & $44.2 \%$ \\
\hline Rifle $-\mathrm{F}$ & 44 & $53.0 \%$ & 21 & $52.5 \%$ & 23 & $53.5 \%$ \\
\hline \multicolumn{4}{|r|}{} & \multicolumn{2}{|c|}{ Chi Square $(\mathrm{X})^{2}=0.427$} & \multicolumn{2}{c|}{$\mathrm{P}=0.808$} \\
\hline
\end{tabular}

Among the AKI patients, 3 were in the risk category, 36 in the injury and 44 in the failure category with the percentage of $3.6 \%, 43.4 \%$ and $53.0 \%$ respectively.

In the expired patients, 23 were in the failure category, 19 were in the injury category, 1 was in the risk category. The percentages were $53.5 \%, 44.2 \%$ and $2.3 \%$ respectively.

This increase in 'failure' percentage was not statistically significant to predict as a marker of mortality. The $\mathrm{p}$ value was 0.808 .

Out of the 83 patients, 58 did not undergo any procedures. 16 underwent hemodialysis and 9 underwent peritoneal dialysis with the percentages of $69.9 \%, 19.3 \%$ and $10.8 \%$ respectively.

In the expired patients, 10 underwent hemodialysis, 4 were on peritoneal dialysis and 29 were not on any support with the percentages of $9.3 \%, 23.3 \%$ and $67.4 \%$ respectively.

These percentages were not statistically significant as the $\mathrm{p}$ value was 0.605

The Mean For Age, Spot Na, Fena, Creatinine

\begin{tabular}{|c|c|c|c|c|c|c|c|}
\hline \multirow{3}{*}{ Parameter } & \multirow{2}{*}{\multicolumn{2}{|c|}{ Total }} & \multicolumn{4}{|c|}{ Outcome } & \multirow{2}{*}{$\begin{array}{c}\text { Mann } \\
\text { Whitney U } \\
\text { Test }\end{array}$} \\
\hline & & & \multicolumn{2}{|c|}{ Discharged } & \multicolumn{2}{|c|}{ Expired } & \\
\hline & Mean & $\mathrm{Sd}$ & Mean & $\mathrm{Sd}$ & Mean & $\mathrm{Sd}$ & P Value \\
\hline Age & 49.96 & 14.23 & 50.28 & 16.13 & 49.67 & 12.39 & 0.616 \\
\hline Initial Creatinine & 2.69 & 1.69 & 2.78 & 1.99 & 2.60 & 1.37 & 0.774 \\
\hline Peak Creatinine & 4.48 & 2.38 & 4.51 & 2.46 & 4.46 & 2.32 & 0.845 \\
\hline Spot Sodium & 91.80 & 29.83 & 67.48 & 29.77 & 56.51 & 29.24 & 0.082 \\
\hline Fena & 1.14 & 0.37 & 1.12 & 0.36 & 1.17 & 0.37 & 0.601 \\
\hline
\end{tabular}

The mean age for the patients developing AKI was 49.96 with SD of 14.23. Among the expired, mean age were 49.67 with SD of 12.39. Mean for the initial creatinine was 2.69 with 1.69 SD. Among the expired 2.60 was the mean initial creatinine.

For the peak creatinine, the mean was 4.48. Regarding the FeNa, the mean was 1.14 with SD 0.37.

Causes Of Aki

\begin{tabular}{|l|c|c|c|c|c|c|}
\hline \multirow{2}{*}{ AKI CAUSE } & \multicolumn{2}{|c|}{ TOTAL } & \multicolumn{4}{c|}{ OUTCOME } \\
\cline { 2 - 7 } & Number & Percent & Number & Percent & Number & Percent \\
\cline { 2 - 7 } & 2 & $2.4 \%$ & 2 & $5.0 \%$ & 0 & $0 \%$ \\
\hline DRUG & 4 & $4.8 \%$ & 2 & $5.0 \%$ & 2 & $4.7 \%$ \\
\hline GN & 6 & $7.2 \%$ & 1 & $2.5 \%$ & 4 & $11.6 \%$ \\
\hline HRS & 6 & $7.2 \%$ & 2 & $5.0 \%$ & 4 & $9.3 \%$ \\
\hline HUS & 38 & $45.8 \%$ & 17 & $42.5 \%$ & 21 & $48.8 \%$ \\
\hline INFECTION & 1 & $1.2 \%$ & 1 & $2.5 \%$ & 0 & $0 \%$ \\
\hline RHABDO & 22 & $26.5 \%$ & 12 & $30 \%$ & 10 & $23.3 \%$ \\
\hline SHOCK & 4 & $4.8 \%$ & 3 & $7.5 \%$ & 1 & $2.3 \%$ \\
\hline TOXIN & & & & & &
\end{tabular}

Among the causes, infection tops the list with 38 cases $(45.8 \%)$. Next comes the shock due to various causes around 22 cases (26.5\%). Other etiologies include HRS and HUS (7.2\% each), toxins and glomerulonephritis $(4.8 \%$ each).

Among the expired patients, infection tops the list and next comes the shock, with $48.8 \%$ and $23.3 \%$ respectively. HRS was $11.6 \%$ among the expired. 


\begin{tabular}{|c|l|c|c|}
\multicolumn{4}{|c}{ Multivariate Logistic Regression To Predict Mortality In Aki } \\
\hline S. No. & PARAMETER & ODDS RATIO (EXP [B]) & SIGNIFICANCE (p) \\
\hline 1 & Oliguria & 9.756 & $<0.001$ \\
\hline 2 & Hypotension & 6.490 & 0.003 \\
\hline 3 & Mechanical Ventilation & 2.288 & 0.135 \\
\hline
\end{tabular}

Multivariate logistic regression analysis was performed to analyze the parameters which were significantly influencing mortality in AKI in the univariate model (with $\mathrm{p}$ value $<0.05$ ). Oliguria and hypotension were the factors which were more likely to predict mortality in AKI with Odds ratio of 9.7 and 6.5 respectively. Mechanical Ventilation also had an Odds ratio of 2.3 in predicting mortality, but it fell short of significance in the final regression model $(\mathrm{p}=0.13)$.

\section{Discussion}

Acute kidney injury is a clinical condition that complicates other diseases and when it is associated with other diseases the mortality and morbidity will increase. Also it can occur as a primary problem with its complications resulting in mortality and morbidity. Acute kidney injury is caused by various etiological factors and environmental factors. After identifying AKI, the foremost thing is to find out the cause for it. There are many studies that are ongoing in the acute kidney injury correlating with various comorbibities. Already plenty of studies have been done on this one; still we are in a state to need know more about it.

Studies were done regarding the epidemiology, etiology, severity and outcome of patients on dialysis. Also AKI had been studied to find the heterogeneous factors in relation to adult and pediatric population, in urban and tropical setting, also in developing countries and developed countries.

To assess the severity of the disease, various criterias were developed to manage them effectively. Studies had been done on these criterias to test the efficacy of the criteria in predicting the disease course. AKI is traditionally classified into three: the community, in hospital and in ICU. The predominant factors causing AKI were different in different settings. Also the mortality is varying with each entity. There are plenty of literatures on acute kidney injury in various scenarios in our western counterpart. On the contrary, there were very limited studies in our Indian population, especially in the southern side.

We conducted the study in the medical intensive care unit, in Government Thiruvannamalai Medical College and Hospital from March 2016 to August 2016. The total admissions were 700 during that period. Of whom 83 patients developed AKI.

The patients who stayed less than 24 hours were excluded from the study and also those who were already labeled as stage 5 CKD on hemodialysis were excluded.

The incidence of AKI in our MICU was $11.9 \%$. According to the western literature the range of incidence was $5 \%-15 \%$ which is comparable to our data.

Regarding the sex distribution $62.7 \%$ were males and $37.3 \%$ were females. There is a male predominance in the data which implies male were prone to development of AKI. Also among the expired patients $62.8 \%$ were males. But these were not statistically significant.

In our study, age distribution is more centered around $\mathbf{5 0}-\mathbf{5 9}$ years of age and in individuals more than 60 years. But among the expired individuals, persons aged $>60$ years tops the list along with the persons between $40-49$ years. These were not significant to take as a predictor of mortality.

Co morbid factors like diabetes, hypertension were less in the AKI patients. More patients developed AKI without these co morbidities. The patients without diabetes and hypertension were more on the expired group. The $\mathrm{p}$ values for these were more than 0.05 .

Spot urine sodium is a marker used in AKI patients. If it is more than 40 which implies tubular dysfunction and intrinsic renal involvement, in the absence of diuretic usage. In 83 patients, $66.3 \%$ had spot urine sodium > 40. Also 77.5\% expired persons had spot urine sodium $>40$. Although it is not fool proof for tubular dysfunction, it proves as predictor of mortality in AKI patients, which is statistically significant. Many times urinary abnormalities in AKI helps in diagnosis of the disease, which is more common in glomerular diseases and in UTI.

In the study group, $55.4 \%$ had active sediments in the urine and in the mortality group $46.8 \%$ had active sediments. But these were not statistically significant.

The renal failure patients were usually categorized into oliguric and non oliguric. It neither differentiates acute and acute on chronic nor does find prerenal or intrinsic renal. Nearly $45.8 \%$ was oliguric in the AKI patients and in the expired group it was $67.8 \%$ which is statistically significant as a predictor of mortality. Oliguria usually occurs in various diseases like cardiac failure, hypovolemic shock, other than renal failure. If it is associated with AKI it is a significant factor in predicting the mortality. 
In acute kidney injury patients $48.2 \%$ were hypotensive, and in the expired group $62.8 \%$ were hypotensive. Hypotensive individuals include those persons who developed hypotension at least one time during their MICU stay. This was statistically significant with a $\mathrm{p}$ value of 0.006 , which predicts the mortality. Thus hypotension in AKI is a significant factor in predicting the mortality.

In MICU setting, patients will be connected to the ventilator due to various reasons. Among the AKI patients in our study $44.5 \%$ were connected to the ventilator and in the expired $55.8 \%$ were connected to the ventilator. Ventilator support is a predictor of mortality in AKI patients in MICU with significant $\mathrm{p}$ value of 0.033 .

Acute kidney injury can occur on previously normal patients or in patients with underlying renal disease. In our study $55.4 \%$ presented as acute and $44.6 \%$ were acute on chronic renal disease. It doesn't have any influence on mortality. Usually underlying diabetes or hypertension had some proteinuria which results in renal injury.

We categorized the patients into prerenal and intrinsic renal based on clinical scenario, FeNa, hydration status and creatinine measurements. In AKI patients $69.9 \%$ were intrinsic renal and $30.1 \%$ were labeled as prerenal. Among the expired patients, $74.4 \%$ were intrinsic renal. Although it is not statistically significant, there was more intrinsic renal failure in the expired group.

Acute kidney injury patients can be managed conservatively or they may undergo dialysis. In our study patients, $69.9 \%$ was managed conservatively and $19.3 \%$ were on HD and $10.8 \%$ on PD. Only $9.3 \%$ of the individuals on HD expired but the ratio is not statistically significant.

In acute kidney injury the severity is assessed with the help of RIFLE criteria which has more sensitivity. Many studies have proved that it is an independent predictor of mortality. But in our study, among the AKI patients $53 \%$ were in the failure category, $43.4 \%$ were in injury category and $3.6 \%$ in risk category. In the expired group, $53.5 \%$ were in the failure category and $44.2 \%$ were in the injury category, but this not statistically significant. This may be due to less sample size and also less numbers in the R category.

Among the continuous variables like age, creatinine, spot $\mathrm{Na}$, the mean and standard deviation were calculated. The Mann Whitney $U$ test was used to find out the significance of the variable in predicting the mortality. The mean for age, peak creatinine, and spot sodium were 49.96, 4.48 and 61.80 respectively. The mean age among the expired was 49.67, spot sodium was 56.51. Regarding the FeNa the mean was 1.17 with the standard deviation of 0.37 but this is also not statistically significant.

In the intensive care setting, patient will be admitted for various diseases involving various organs. Certain diseases were more prone for developing AKI. In our MICU, infection causes $45.8 \%$ of AKI. Shock causes $26.5 \%$ of the cases, remaining cases were caused by the hepato renal syndrome, hemolytic uremic syndrome, glomerulonephritis, toxins, and drugs in decreasing order of percentage. Among the expired, infection was the predominant cause of AKI with a percentage of $48.8 \%$ and shock causes $23.3 \%$. The others were HRS, HUS, glomerulonephritis and toxin in decreasing order. Infection is the major cause of AKI in our study, which has been confirmed by many other studies, next was the shock from various causes which results in AKI. Infection is also the major cause of mortality in patients with AKI. Copper sulphate poisoning is the most common cause of toxin induced AKI in our MICU. But the mortality is less in copper sulphate due to forced alkaline diuresis as a treatment modality. There were only two cases of AKI occurred due to drugs. But there were no deaths. Due to more number of decompensated liver disease patients getting admitted in our MICU, a significant number of cases of AKI were caused by HRS, apart from infection causing AKI in the DCLD patients.

The above told statistical analysis was done by the univariate analysis, Pearson chi- square test to predict the mortality with the associated variables. Further to increase the statistical significance, the factors which predict the mortality with significance according to univariate analysis were included in the multivariate regression analysis. It confirmed that oliguria and hypotension significantly predicted the mortality. The mechanical ventilation predicts with less significance.

Hou et $\mathbf{a l}^{\mathbf{3 0}}$ did a study on AKI in early days and reported a incidence of 4.9 percentage which was less comparable to the present status and the mortality rate was $25 \%$. Few years later, Nash et $\mathbf{a l}^{\mathbf{3 1}}$ found that the inhospital AKI incidence was around $7.2 \%$, and the mortality rate was $19.4 \%$. The predominant causes were decreased perfusion, toxins and major surgeries. These were the earlier data.

Sean bagshaw et al reported from a multicenter study which was conducted in Australian ICUs that, incidence of AKI in ICU was $5.2 \%$ with a yearly increase of $2.8 \%$, the mortality rate of AKI patients was $42.7 \%$. The total duration of stay was more in the survivors than those expired.

Schaefer $\mathbf{J H}$ et $\mathbf{a l}^{25}$ found out the outcome predictors of acute kidney injury in ICU setting. They reported that the mortality rate was $56.7 \%$ in AKI patients in ICU. Also they found mechanical ventilation, hypotension were the significant predictors of mortality. The results of this study closely resembled our study results. 
Brivet FG et $\mathbf{a l}^{\mathbf{2 6}}$ did a multicenter evaluation of AKI in ICU. They preferably analyzed the severe AKI. Their sample size was 360 . Their results showed a mortality rate of 58\%, which is higher than that of our study. The predictor of mortality was age, oliguria, sepsis, severity of illness, delayed renal failure, and previous hospitalization. The predictor of mortality in this study partially resembles our study. Among the AKI patients 16 were prerenal, 282 were intrinsic renal and 17 were post renal. As in our study the intrinsic renal group was more.

Abosaif NY et $\mathbf{a l}^{27}$ did a study on the outcome of AKI patients in intensive care setting according to RIFLE. They had 60 patients in risk category, 56 in injury category and 43 in failure category. They reported that, those patients with failure category had increased death rate. They confirmed the ability of RIFLE criteria in predicting mortality. Also they found the RIFLE is correlating with the severity illness scores like APACHE II and SAPS score. In our study there were fewer patients in the R category. Also we couldn't prove that RIFLE criteria predict the mortality. As the severity increases the death rate doesn't show a rise in statistically significant manner.

Chologitas et $\mathbf{a l}^{\mathbf{2 8}}$ did a study among the decompensated liver disease patients in ICU to find out the correlation of mortality with the severity of AKI. The overall mortality was $61.2 \%$. They analyzed with multivariate regression method, which showed RIFLE is an independent factor associated with mortality. But it is less useful than other severity scores like SOFA, APACHE II.

The famous PICARD ${ }^{32}$ (the program to improve care in acute renal disease) study was conducted in 5 centers as a prospective observational cohort study over 3 years. They found an incidence of $25 \%-60 \%$, and reported a heterogenicity of distribution of AKI among all aspects. The common causes include ATN, intrinsic renal disease sepsis, nephrotoxin administration, cardiac diseases and liver diseases. This mainly gave a conclusion of changing trends in the epidemiology of AKI.

The BEST study ${ }^{33}$ (the beginning and ending supportive therapy for the kidney) is the largest prospective cohort study conducted over this topic. The mortality rate was around $60 \%$. The predominant causes were septic shock, postoperative states, cardiac diseases and toxin administration. The predictors of mortality were old age, sepsis, oliguria, blood urea nitrogen, severity score. Our study partially resembles this study in certain variables.

Ostermann et $\mathbf{a l}^{\mathbf{2 9}}$ evaluated the utility of RIFLE in ICU setting. They found that AKI had an incidence of $35.8 \%$. Among that $17.2 \%$ were in risk category, $11 \%$ in injury category and $7.6 \%$ in failure category. The mortality was more in the failure category. RIFLE criteria predict the outcome of renal failure but the associated multi organ dysfunction, severity of illness for which patients were admitted had a more significant impact in determining the outcome.

Cruz et al did a prospective study and calculated the AKI incidence in ICU setting. It was around $10.8 \%$, the incidence closely resembles our study and 3.3\% required dialysis. Among the AKI patients, $19 \%$ were in risk, $35 \%$ in injury, and $46 \%$ in failure category. As in our study, this study also had more number of in failure category. The most common causes of AKI were prerenal $38.9 \%$ and sepsis $25.6 \%$.

In the Indian studies for example, study on hospital acquired AKI conducted by anupama kaul et al over 12 months in a prospective manner, showed that baseline creatinine value, maximum RIFLE category and decreased urine output and metabolic acidosis were the predictors of mortality. They concluded that the epidemiology of AKI has been more or less similar to the western data.

Recently D Juneja et al did a study in ICU of a tertiary care hospital in New Delhi. They reported that patients with increased severity of AKI according to RIFLE had increased mortality. The mortality for the patients in failure group was $38 \%$ which is lower than our mortality rate.

Sural $\mathbf{S}$ et al did a study on acute kidney injury in ICU. Their results showed, the mortality rate was around $90 \%$. The primary reasons for admissions were sepsis and multi organ dysfunction. They found out MODS is the only predictor of mortality with statistical significance.

Although the mortality rate in our study is high, it is comparable to the western data. Among the AKI patients, more common reasons for admission in ICU were sepsis, decompensated liver disease and cardiovascular diseases.

Although many studies have been proved the RIFLE criteria as a predictor of mortality our study couldn't prove that. This may be due to less sample size. Analysis done by multivariate regression showed oliguria, hypotension were the significant predictors of mortality. Ventilator support as a predictor of mortality has somewhat less statistical significance.

\section{Limitations of our study:}

- The sample size is small.

- It has been done in a single center.

- The postoperative cases, trauma cases and surgical cases were not included.

- We didn't use other severity scores like APACHEII, SAPS and SOFA. 
- Only the in-hospital mortality has been calculated.

- We didn't take urine output in consideration to diagnose AKI.

- Single group of population has been studied, so we cannot find out heterogeneous epidemiology of acute kidney injury.

\section{Summary and conclusion}

Acute kidney injury, a common problem in ICU, has a strong impact in the mortality and morbidity. Although there are rampant studies available in the west, there are less than a handful of studies in south India. We had few similarities and dissimilarities in comparison to the western literature.

\section{Results comparable to study done elsewhere:}

- Incidence of AKI is $11.7 \%$

- Mortality rate is $51.8 \%$

- Most common causes of AKI are sepsis, shock, and hepato renal syndrome.

- Predictors of mortality are persistent oliguria requiring renal replacement therapy, hypotension and ventilator support.

- Incidence of AKI is more than acute on chronic kidney disease.

Results dissimilar to study done elsewhere:

- Severity of AKI as per RIFLE did not correlate with mortality.

- Patients in RIFLE(R) were less in number.

- Age had no say in the mortality.

- Coexistent diabetes and hypertension did not influence the mortality.

There is one parameter, which is not taken into consideration in other studies (to the best of our knowledge), which is an independent predictor of mortality, is spot urine sodium (> 40). Further studies on large scale are required to prove its significance.

In short, infections and hypotension are the most common cause of mortality. Diligent care should be taken to find the etiology and to maintain fluid homeostasis. Patients who are oliguric and/or on ventilator should be managed with special precautions, as they are significant predictors of mortality.

[1]. Brenner and Rector's the kidney 8th edition.

\section{References}

[2]. William F. Ganong review of medical physiology 22nd edition.

[3]. Harrison's principles of internal medicine 18th edition.

[4]. Robert W Schrier manual of nephrology 7 th edition.

[5]. Bellomo R, Ronco C, Kellum JA et al. Acute renal failure-definition, outcome measures, animal models, fluid therapy and information technology needs: the Second International Consensus Conference of the Acute Dialysis Quality Initiative (ADQI) Group. Crit Care 2004; 8:R204-R212

[6]. Jurgen floege, Richard J.Johnson, John Feehaly comprehensive clinical nephrology 4th edition.

[7]. De Vriese AS. Prevention and treatment of acute renal failure in sepsis. J Am Soc Nephrol. 2003; 14: 792-805.

[8]. Riedemann NC, Guo RF, Ward PA. The enigma of sepsis. J ClinInvest.2003; 112: 460-467.

[9]. Schrier RW, Wang W. Acute renal failure and sepsis. N Engl J Med. 2004; 351:159-169.

[10]. Shroyer AL, Coombs LP, Peterson ED, et al. The Society of Thoracic Surgeons: 30-day operative mortality and morbidity risk models. Ann Thorac Surg. 2003; 75: 1856-1864; discussion 64-65.

[11]. Thakar CV, Arrigain S, Worley S, et al. A clinical score to predict acute renal failure after cardiac surgery. J Am Soc Nephrol.2005;16:162-1

[12]. Ronco C, House AA, Haapio M. Cardio renal syndrome: Refining the definition of a complex symbiosis gone wrong. Intensive Care Med. 2008; 34: 957-962.

[13]. Oxford text book of Nephrology.

[14]. Duvoux C, Zanditenas D, Hezode C, et al. Effects of noradrenalin and albumin in patients with type I hepatorenal syndrome: A pilot study. Hepatology. 2002; 36: 374-380.

[15]. Alessandria C, Ottobrelli A, Debernardi-Venon W, et al. Noradrenalin vs. terlipressin in patients with hepatorenal syndrome: A prospective, randomized, unblinded, pilot study. J Hepatol. 2007; 47: 499-505.

[16]. Lameire N, Van Biesen W, Van holder R. The changing epidemiology of acute renal failure. Nat Clin Pract Nephrol 2006; 2: 364377.

[17]. Mehta RL, Pascual MT, Soroko S, et al. Spectrum of acute renal failure in the intensive care unit: The PICARD experience. Kidney Int. 2004; 66: 1613-1621.

[18]. Ronco C. Continuous dialysis is superior to intermittent dialysis in acute kidney injury of the critically ill patient. Nat Clin Pract Nephrol 2007; 3: 118-119.

[19]. Carvounis CP, Nisar S, Guro-Razman S. Significance of the fractional excretion of urea in the differential diagnosis of acute renal failure. Kidney Int 2002; 62: 2223-2229.

[20]. Molitoris BA, Levin A, Warnock DG, et al. improving outcomes of acute kidney injury: report of an initiative. Nat Clin Pract Nephrol 2007; 3: 439-442.

[21]. Parikh C, Cantley L, Devarajan P, et al. Biomarkers of acute kidney injury - early diagnosis, pathogenesis and recovery. J Investig Med 2007; 55(7): 333-340. 
[22]. Nguyen MT, Devarajan P. Biomarkers for the early detection of acute kidney injury. Pediatr Nephrol. 2008; 23: 2151-2157.

[23]. Perazella MA, Coca SG, Kanbay M, et al. Diagnostic value of urine microscopy for differential diagnosis of acute kidney injury in hospitalized patients. Clin J Am Soc Nephrol. 2008; 3: 1615-1619.

[24]. Preston RA, Stemmer CL, Materson BJ, et al: Renal biopsy in patients 65 years of age or older: An analysis of the results of 334 biopsies. J Am Geriatr Soc 1990; 38: 669-674

[25]. Intensive Care Med. 1991; 17(1):19-24.Outcome prediction of acute renal failure in medical intensive care. Schaefer JH, Jochimsen F, Keller F, Wegscheider K, Distler A. Source. Department of Internal Medicine, Free University, Berlin, FRG.

[26]. Crit Care Med. 1996 Feb; 24(2): 192-8.Acute renal failure in intensive care units--causes, outcome, and prognostic factors of hospital mortality; a prospective, multicenter study. French Study Group on Acute Renal Failure. Brivet FG, Kleinknecht DJ, Loirat P, Landais PJ. Source Department of Intensive Care, Hospital Antoine Béclère Clamart, France.

[27]. Am J Kidney Dis. 2005 Dec; 46(6):1038-48. The outcome of acute renal failure in the intensive care unit according to RIFLE: model application, sensitivity, and predictability. Abosaif NY, Tolba YA, Heap M, Russell J, El Nahas A M. Source Sheffield Kidney Institute and Intensive Care Unit, Northern General Hospital, University of Sheffield, UK.

[28]. J Gastroenterol Hepatol. 2009 Oct; 24(10): 163947. RIFLE classification as predictive factor of mortality in patients with cirrhosis admitted to intensive care unit. Cholongitas E, Calvaruso V, Senzolo M, Patch D, Shaw S, O' Beirne J, Burroughs AK. Source the Royal Free Sheila Sherlock Liver Centre and Department of Surgery, Royal Free Hospital, Hampstead, London NW3 2QG, UK.

[29]. Crit Care Med. 2007 Aug; 35(8):1837-43; quiz 1852.Acute kidney injury in the intensive care unit according to RIFLE. Ostermann M, Chang RW. Source; Department of Intensive Care, Guy's and St Thomas' Hospital, London, UK. marlies@ostermann. freeserve.co.uk

[30]. Hou SH, Bushinsky DA, Wish JB, Cohen JJ, and Harrington JT: Hospital-acquired renal insufficiency: A prospective study. Am J Med74 : 243-248,1983

[31]. Nash K, Hafeez A, Hou S: Hospital-acquired renal insufficiency. Am J Kidney Dis39 : 930-936, 2002

[32]. Mehta RL, Pascual MT, Soroko S, Savage BR, Himmelfarb J, Ikizler TA, Paganini EP, and Chertow GM: Spectrum of acute renal failure in the intensive care unit: The PICARD experience. Kidney Int66:1613-1621, 2004

[33]. Uchino S, Bellomo R, Morimatsu H, Morgera S, Schetz M, Tan I, Bouman C, Macedo E, Gibney N, Tolwani A, Doig GS, Oudemans van Straaten H, Ronco C, Kellum JA: External validation of severity scoring systems for acute renal failure using a multinational database. Crit Care Med33: 1961- 1967, 2005. 